\title{
Quantifying the contribution of land use change to surface temperature in the lower reaches of the Yangtze River
}

\author{
Xueqian Wang ${ }^{1,2}$, Weidong Guo ${ }^{1,2}$, Bo Qiu ${ }^{1,2}$, Ye Liu ${ }^{1,2}$, Jianning Sun ${ }^{1,2}$, and Aijun Ding ${ }^{1,2}$ \\ ${ }^{1}$ CMA-NJU Joint Laboratory for Climate Prediction Studies, Institute for Climate and Global Change Research, \\ School of Atmospheric Sciences, Nanjing University, Nanjing, China \\ ${ }^{2}$ Joint International Research Laboratory of Atmospheric and Earth System Sciences, Nanjing, China \\ Correspondence to: Weidong Guo (guowd@nju.edu.cn)
}

Received: 16 November 2016 - Discussion started: 21 November 2016

Revised: 16 March 2017 - Accepted: 17 March 2017 - Published: 18 April 2017

\begin{abstract}
Anthropogenic land use has a significant impact on climate change. Located in the typical East Asian monsoon region, the land-atmosphere interaction in the lower reaches of the Yangtze River is even more complicated due to intensive human activities and different types of land use in this region. To better understand these effects on microclimate change, we compare differences in land surface temperature $\left(T_{\mathrm{S}}\right)$ for three land types around Nanjing from March to August, 2013, and then quantify the contribution of land surface factors to these differences $\left(\Delta T_{\mathrm{S}}\right)$ by considering the effects of surface albedo, roughness length, and evaporation. The atmospheric background contribution to $\Delta T_{\mathrm{S}}$ is also considered based on differences in air temperature $\left(\Delta T_{\mathrm{a}}\right)$. It is found that the cropland cooling effect decreases $T_{\mathrm{S}}$ by $1.76^{\circ}$ and the urban heat island effect increases $T_{\mathrm{s}}$ by $1.25^{\circ}$. They have opposite impacts but are both significant in this region. Various changes in surface factors affect radiation and energy distribution and eventually modify $T_{\mathrm{s}}$. It is the evaporative cooling effect that plays the most important role in this region and accounts for $1.40^{\circ}$ of the crop cooling and $2.29^{\circ}$ of the urban warming. Moreover, the background atmospheric circulation is also an indispensable part in land-atmosphere feedback induced by land use change and reinforces both these effects.
\end{abstract}

\section{Introduction}

Land-use-land-cover change (LULCC) has been widely investigated in the past few decades, and it has been found that more than half of the land surface on Earth has been exploited by human (Baldocchi, 2014). Robust evidence indicates that the impact of LULCC on temperature is obvious, and this impact depends on different types of land surface transformation. Deforestation usually has a warming effect at lower latitudes and a cooling effect at mid- to high latitudes (Lee et al., 2011). Global deforestation may result in cooling (Pitman et al., 2009; Davin and Noblet-Ducoudré, 2010; Betts et al., 2007) and amplify diurnal temperature variance (Alkama and Cescatti, 2016). The urban heat island (UHI) is one of the most significant human-induced phenomena, and it usually results in apparent warming in urban areas compared to the surrounding rural areas. The UHI effect depends on latitude, climate regime, urban area size, and time of the season (Kalnay and Cai, 2003; McCarthy et al., 2010; Zhao et al., 2014; Basara et al., 2008; Lin et al., 2016). Agriculture often leads to cooling temperature in different patterns, and the cooling effect can usually be magnified when it comes to irrigation (Campra et al., 2008; Kueppers et al., 2007; Lobell et al., 2006; Zhang et al., 2011). For this reason, analyzing different types of land use plays an important role not only in evaluating climate change on different spatial scales (Alkama and Cescatti, 2016; Baldocchi and Ma, 2013; Huang et al., 2008; Wang et al., 2010; Hari et al., 2016), but also in improving the predictive capacity of models (Huang et al., 2015; Niu et al., 2011; Zhang et al., 2015). Although there have been many studies concentrating on LULCC, they 
rarely compare the differences in the mechanisms behind the land-atmosphere interaction with different types of land use.

The effects of anthropogenic land use on local climate are complicated, with a series of stabilizing and reinforcing feedbacks (Baldocchi, 2014). Although surface albedo change has been widely analyzed as the strongest climate forcing (Campra et al., 2008), CIPCC (2013) emphasizes that it is not the only effect of LULCC because LULCC also causes other changes that do not affect the radiative process but can also significantly influence the surface temperature $\left(T_{\mathrm{S}}\right)$. These changes, such as surface roughness (Davin and Noblet-Ducoudré, 2010; Kanda, 2007) and evapotranspiration changes (Pitman et al., 2009), are more uncertain and difficult to quantify, but they exert essential influences on the radiative process and energy redistribution on the land surface (Baldocchi and Ma, 2013; Campra et al., 2008; Yang et al., 2014), and thereby cause obvious differences in $T_{\mathrm{S}}$ over various land surface types under different climate backgrounds (Biggs et al., 2008; Luyssaert et al., 2014).

To understand the influence of LULCC, it is important to quantify the contributions of different surface factors for each type of land use. Juang et al. (2007) proposed the method to decompose the observed change in $T_{\mathrm{S}}$ based on surface energy balance, and this method was refined later by Luyssaert et al. (2014). Lee et al. (2011) presented a new metric and attributed the change in $T_{\mathrm{S}}$ to radiation, convection, and evaporation. Chen and Dirmeyer (2016) added the atmospheric background effect to the metric proposed by Lee et al. (2011). This method can be used to calculate each factor's contribution to $T_{\mathrm{S}}$ in areas with different vegetation cover (Bright et al., 2014; Li et al., 2015) as well as urban area (Zhao et al., 2014).

The lower reaches of the Yangtze River valley, which is located in the typical East Asian monsoon region, is one of the regions with the most intensive human activities around the world. Rapid urbanization, industrialization, expansion of farmland, animal husbandry, deforestation, and afforestation are common features in this region. In the monsoon region, LULCC affects climate not only by influencing local convection through radiation and surface heat fluxes, but also by influencing the monsoon onset and weakening related precipitation (Hsu and Liu, 2003; Xue et al., 2004). However, both flux observations and characteristic analyses, let alone quantitative analysis, are very limited in the lower reaches of the Yangtze River valley (Gao, 2003; Bi et al., 2007). In this study, the contributions of different surface land factors to surface temperature are calculated based on an analysis of data collected at several sites, where the land use type includes crop, grass, and urban area (Guo et al., 2016). We first quantitatively compare the influences of several different surface factors on $T_{\mathrm{S}}$ over different types of managed land and then demonstrate that the Bowen ratio effect dominates the feedback of land use change to surface temperature in this region, while other factors play a secondary role.

\section{Data and methods}

\subsection{Observation sites and data}

The measurements used in this study were collected at three sites in the lower reaches of the Yangtze River. The urban site, where the average building height is $19.7 \mathrm{~m}$, is located at Dangxiao, the central urban area of Nanjing $\left(32^{\circ} 2^{\prime} 24^{\prime \prime} \mathrm{N}\right.$, $\left.118^{\circ} 47^{\prime} 24^{\prime \prime} \mathrm{E}\right)$. The other two sites are both located at around $\left(31^{\circ} 43^{\prime} 08^{\prime \prime} \mathrm{N}, 118^{\circ} 58^{\prime} 51^{\prime \prime} \mathrm{E}\right)$ in Lishui county and classified as a grassland site and a cropland site. The grass height is about $60 \mathrm{~cm}$. Rice grows in the summer (mid June to early November), and wheat grows in the winter (from mid to late November to early June of next year) nearby the cropland site, with the largest plant height being $75 \mathrm{~cm}$.

In this study, sensible and latent heat fluxes are measured at $30 \mathrm{~min}$ intervals by the eddy covariance system (EC3000, Campbell) deployed at $3 \mathrm{~m}$ height over the grass site and crop site and at $36.5 \mathrm{~m}$ height above the $22 \mathrm{~m}$ high building at the urban site. The sampling frequency is $10 \mathrm{~Hz}$ for measurements by the data acquisition logger (CR5000). We have applied strict corrections such as coordinate rotation correction (Wilczak et al., 2001), frequency response correction (Moore, 1986), Webb-Pearman-Leuning (WPL) correction (Webb et al., 1980), and quality control (Foken et al., 2004) to all the flux measurements. The measurements contain micrometeorological elements of air temperature (HMP45CL, Vaisala), precipitation (TE525MM-L, Texas Electronics), and surface radiation fluxes including downward and upward shortwave (CM21, Kipp \& Zonen) and long-wave (CG4, Kipp \& Zonen) fluxes at half-hour intervals. Additional information about both the observations and sites such as the location and spatial distribution of sites can be found in a previous study (Guo et al., 2016).

The analysis focuses on March to August in 2013. This is because the eddy covariance method is assumed to work well only when turbulence can develop fully. To quantify the different contributions to $\Delta T_{\mathrm{s}}$ more accurately, we use the integrated turbulence characteristics (ITCs) proposed by Foken (Foken and Wichura, 1996) to remove the data with low quality. Such a standard was also adopted by the FLUXNET program (Foken et al., 2004).

\subsection{Methodology}

In an ideal state, the surface energy balance can be expressed as

$R_{\mathrm{n}}+\mathrm{AH}=H+\mathrm{LE}+G$,

where $R_{\mathrm{n}}$ is the net radiation calculated from $R_{\mathrm{n}}=\mathrm{DSR}+$ DLR - USR - ULR and CDSR, DLR, USR, and ULR are the daily downward shortwave radiation, downward long-wave radiation, upward shortwave radiation, and upward longwave radiation, respectively. Anthropogenic heat $(\mathrm{AH})$ flux is more obvious in urban areas than in rural areas, but it is 
difficult to measure accurately. $H$ and LE are the daily average sensible and latent heat flux. $G$ includes the heat flux at the surface of soil or buildings and the thermal storage in the canopy, and it is relatively small. In this paper, we only discuss the differences between $R_{\mathrm{n}}$, LE, and $H$ on the basis of the observations at the urban area of Nanjing and the countryside.

Following the method proposed by Lee et al. (2011) and refined by Chen and Dirmeyer (2016), the biophysical mechanism can be expressed as a temperature change and decomposed into three direct factors, i.e. radiation balance, aerodynamic resistance, and evaporation, and one indirect factor of air temperature on a larger scale. Therefore, ignoring $\mathrm{AH}$ and $G$ in an urban area, the daily surface temperature change can be approximated by

$$
\begin{gathered}
\Delta T_{\mathrm{s}} \approx \frac{\lambda_{0}}{1+f} \Delta S+\frac{-\lambda_{0}}{(1+f)^{2}} R_{\mathrm{n}}^{*} \Delta f_{1} \\
+\frac{-\lambda_{0}}{(1+f)^{2}} R_{\mathrm{n}}^{*} \Delta f_{2}+\Delta T_{\mathrm{a}},
\end{gathered}
$$

with

$$
\begin{aligned}
& f=\frac{\lambda_{0} \rho C_{p}}{r_{\mathrm{a}}}\left(1+\frac{1}{\beta}\right) \\
& \Delta f_{1}=\frac{-\lambda_{0} \rho C_{p}}{r_{\mathrm{a}}}\left(1+\frac{1}{\beta}\right) \frac{\Delta r_{\mathrm{a}}}{r_{\mathrm{a}}}, \\
& \Delta f_{2}=\frac{-\lambda_{0} \rho C_{p}}{r_{\mathrm{a}}} \frac{\Delta \beta}{\beta^{2}}
\end{aligned}
$$

where $\Delta T_{\mathrm{S}}$ is the difference in the surface temperature between other managed sites and a natural grass site. $\lambda_{0}=$ $1 / 4 \varepsilon \sigma T^{3}$ is the local climate sensitivity, $f$ is the energy redistribution factor, $S=$ DSR - USR is net shortwave radiation, and $\Delta S$ is the difference between the managed site and the grass site. $R_{\mathrm{n}}^{*}=(1-\alpha) \mathrm{DSR}+\mathrm{DLR}-(1-\varepsilon) \mathrm{DLR}-\varepsilon \sigma T_{\mathrm{a}}^{4}$ is the apparent net radiation, $\alpha=\mathrm{USR} / \mathrm{DSR}$ is albedo, $\varepsilon$ is the surface emissivity, and $\sigma$ is the Stefan-Boltzmann constant. DSR and USR are the daily averages of these solar radiations at half-hour intervals during the period from 06:00 to 18:00 LST. $T_{\mathrm{a}}$ is the air temperature at reference height.

We regard the grass site, with local native vegetation, as the base site. The terms on the right-hand side of Eq. (2) shows that the contributions to $\Delta T_{\mathrm{S}}$ are from radiation change (term 1), aerodynamic resistance change (term 2) related to aerodynamic resistance $\left(r_{\mathrm{a}}\right)$ which represents the surface roughness effect, and evaporation change (term 3 ) related to the Bowen ratio ( $\beta=H / \mathrm{LE})$. Term 2 and term 3 are the two components associated with the energy redistribution.

In the sites covered by vegetation, the aerodynamic resistance can be expressed as (Verhoef and De Bruin, 1997)

$r_{\mathrm{a}}=\frac{1}{\kappa u_{*}}\left[\ln \frac{Z_{m}-d}{Z_{0 m}}+\ln \frac{Z_{m}}{Z_{0 h}}-\Psi_{h}(\zeta)\right]$,

where $Z_{0 m}$ is the aerodynamic roughness length, which can be given by the independent method (Chen et al.,

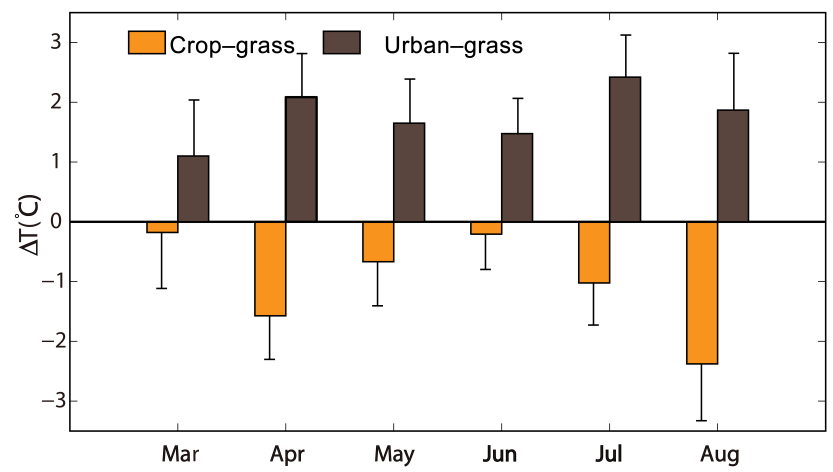

Figure 1. Differences in surface temperature between different sites in Nanjing from March to August 2013. Error bars represent 1 SD for each month.

1993); $\Psi_{h}(\zeta)$ is the stability correction function for temperature; and $\ln \frac{Z_{0 m}}{Z_{0 h}}=0.13\left(\frac{Z_{0 m} u_{*}}{v}\right)^{0.45}$ (Zeng and Dickinson, 1998), where $v$ is the viscosity coefficient with a value of $1.46 \times 10^{-5} \mathrm{~m}^{2} \mathrm{~s}^{-1}$. But in an urban area, because the wind profile cannot be applied well, we calculate the aerodynamic resistance from

$r_{\mathrm{a}}=\frac{\rho C_{p}\left(T_{\mathrm{s}}-T_{\mathrm{a}}\right)}{H}$.

\section{Results}

\subsection{Differences in surface temperature}

Due to the East Asian monsoon anomaly and decreased moisture convergence, 2013 is an extremely dry year in southern China, where the summer precipitation decreased by more than $78 \%$ of the average amount and broke the historical record of the past 50 years (Yuan et al., 2016). The drought in 2013 was especially severe in the mid to lower reaches of the Yangtze River. Under the same dry conditions, different land use types cause different feedbacks to surface temperature $\left(T_{\mathrm{S}}\right)$ and other surface characteristics. To compare the influence of different land use types on microclimate, the surface temperature change $\left(\Delta T_{\mathrm{S}}\right)$ from grassland to cropland and to urban area is quantified.

Monthly variations of $T_{\mathrm{S}}$ differences $\left(\Delta T_{\mathrm{S}}\right)$ between crop and grass sites and between urban and grass sites are presented in Fig. 1. During the entire growing season, cropland had an obvious cooling effect, which was strengthened when it came to irrigation (Kueppers et al., 2007; Lobell et al., 2006). The extremely large differences between crop and grass sites were $-1.75^{\circ}$ in April and $-2.46^{\circ}$ in August (Fig. 1a), with less precipitation in these months (Guo et al., 2016). However, the cooling effect of only $0.34^{\circ}$ in June was relatively small because wheat harvest and straw burning increased $T_{\mathrm{S}}$ in the cropland site. By contrast, the UHI effect 

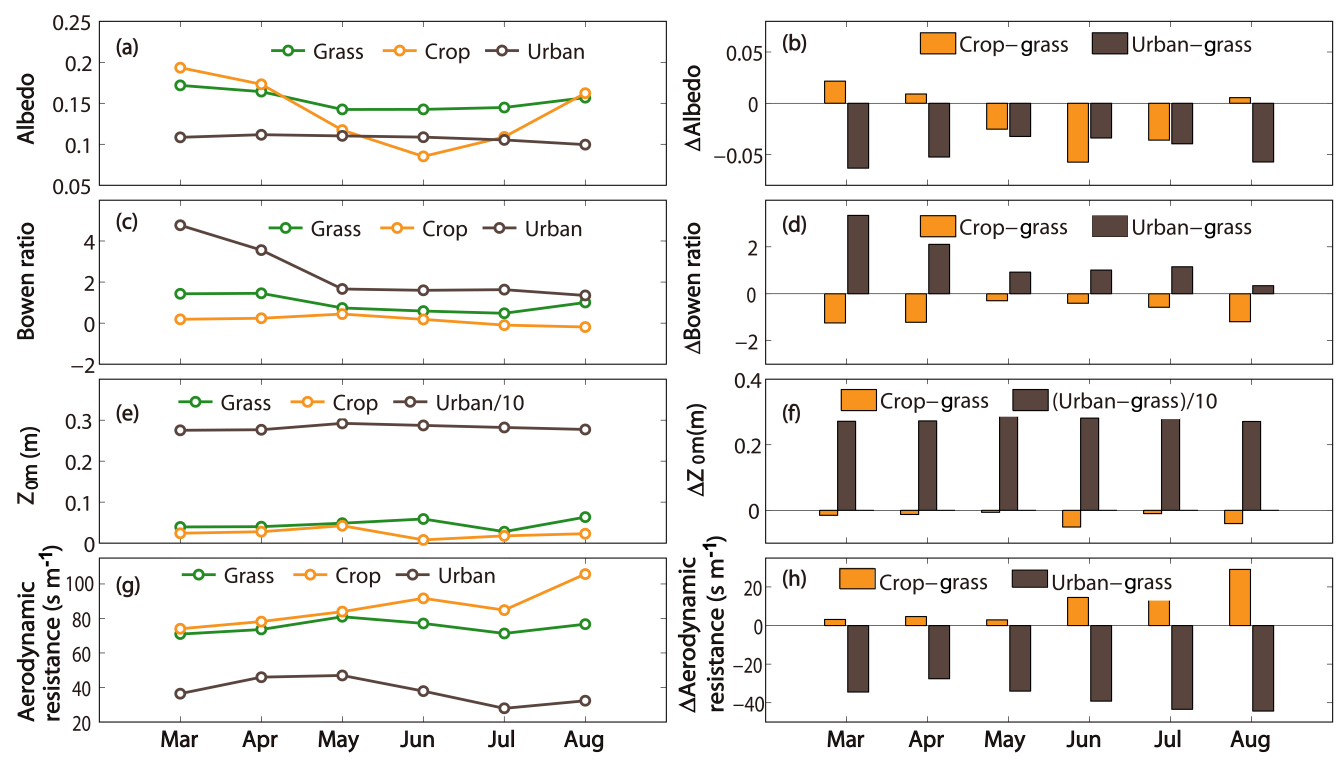

Figure 2. Monthly variations of different factors at the three sites and the differences between the other two sites and the grass site in Nanjing from March to August 2013: (a, b) albedo, (c, d) the Bowen ratio, (e, f) surface roughness, and (g, h) aerodynamic resistance.

resulted in at least $1^{\circ}$ higher temperature at the urban site than at the rural sites in each month of the growing season. The extremely warm and dry conditions in April and July were more evident in the urban area than at the grassland site (Guo et al., 2016), with maximum values of a $1.95^{\circ}$ higher temperature in April and $2.17^{\circ}$ more in July. Comparing different land types, it is clear that land use influences the local $T_{\mathrm{S}}$ to a large extent and makes it more complicated. Cropland cooling and UHI effects are both obvious in the East Asian monsoon region.

\subsection{Variations and differences in land surface factors}

The characteristics of physical processes at different surface types can be represented by surface factors, including albedo, the Bowen ratio, surface roughness, and aerodynamic resistance. These factors reflect the momentum, heat, and moisture exchanges between land and atmosphere (Baldocchi and Ma, 2013; Bright et al., 2015; IPCC, 2013). Figure 2 shows the monthly variation and differences of these factors by averaging their daily values across the crop, urban, and grass sites. The error bar is given as $1 \mathrm{SD}$ for the monthly averages of daily $T_{\mathrm{s}}$. Different land types with different surface color, permeable rate, heat content, and surface roughness have different properties and impacts in the land-atmosphere interactions. Human modifications in the urban area make it more obviously different from grassland and cropland. Except for the extremely low albedo in cropland from May to June, the differences in albedo, the Bowen ratio, and surface roughness between crop site and grass site are the opposite of the differences between urban site and grass site.
Monthly variation of surface albedo shows that the albedo in grassland gradually decreased from March to June but slightly increased in July and August because of the drought. Due to a series of agricultural activities including wheat harvest, straw burning, and rice irrigation from early May to mid June, the albedo for the cropland decreased quickly and reached a minimum value in June due to the burning and then increased when rice started growing. In this way, the difference in albedo $(\Delta \alpha)$ between the crop and grass site was negative from May to July, with the extreme value of -0.06 in June. Monthly $\Delta \alpha$ between the urban and the grass site remained negative during the whole growing season (Fig. 2b). To a certain extent, the Bowen ratio is a measurement of dry and wet conditions of the surface. Sufficient soil water content benefits energy exchange through higher LE and lower Bowen ratio. The largest differences occurred in March, with a value of 2.8 at the urban site and -1.24 at the crop site. With the lack of precipitation in August, the increase in $\beta$ obviously occurred at the grassland site but not at the other two managed land sites (Fig. 2c). The Bowen ratio at the crop site was always low in the growing season because of sufficient water supply.

Moreover, Fig. 2e and $\mathrm{f}$ show that the urban surface roughness $\left(Z_{0 m}\right)$ is much higher than that for land with vegetation cover. The average surface roughness length for the urban area is $2.82 \mathrm{~m}$ higher than for the suburban area. When it comes to sites with vegetation cover, it is shown that $Z_{0 m}$ for the grassland site was a little higher than that for the cropland site and the extreme difference was $-0.05 \mathrm{~m}$ in June due to the wheat harvest. Contrary to the differences in $Z_{0 m}$, the aerodynamic resistance at the urban site was obviously lower than that at other sites during the entire growing season. The 


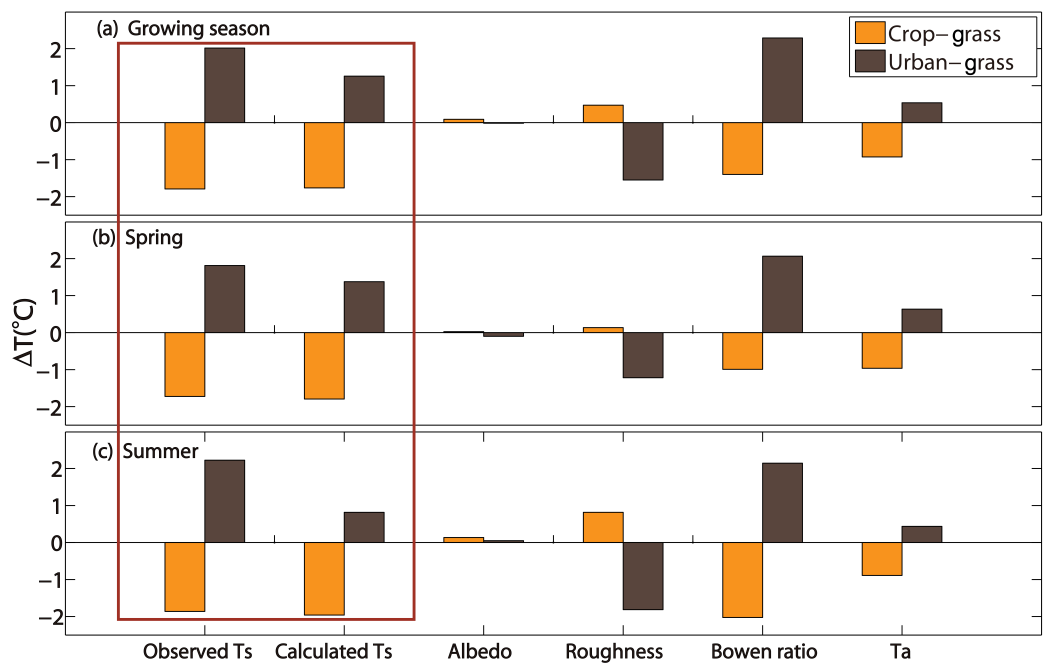

Figure 3. Contributions to the differences in surface temperature between urban and cropland sites and the grassland site due to radiation, aerodynamic resistance, evaporation, and air temperature $\left(T_{\mathrm{a}}\right)$ in (a) the growing season, (b) spring, and (c) summer 2013.

grass site and crop site had a similar trend of aerodynamic resistance in the spring but a relatively large difference in the summer. Unlike the $Z_{0 m}$ variation, the aerodynamic resistance in grassland was much higher than that in the urban area but a little lower than that in cropland. The largest differences in aerodynamic resistance between urban area and grassland and between cropland and grassland both occurred in August, with values of -44.36 and $29.08 \mathrm{~s} \mathrm{~m}^{-1}$, respectively.

\subsection{Attribution of the differences in micrometeorological elements}

In the land-atmosphere interaction process under the same climate background, different types of land use with different surface factors can affect the radiation budget and redistribution of surface sensible and latent heat flux and eventually affect local surface temperature. Figure 3 shows the attribution of $\Delta T_{\mathrm{S}}$ to both direct surface factors and indirect atmospheric effect at the crop and urban sites. The $\Delta T_{\mathrm{S}}$ attributed to roughness was calculated by aerodynamic resistance. Thus, a negative value means high roughness and cooling effect. It is clear that the dominant modification was caused by the evaporation represented by the Bowen ratio, the value of which was even comparable to the observed $\Delta T_{\mathrm{s}}$ in the lower reaches of the Yangtze River. While the $\Delta T_{\mathrm{s}}$ driven by surface roughness and evaporation were of opposite sign at the crop site and the urban site, contributions of the two factors are both strengthened from the spring to summer. Even though the low vegetation height with low $Z_{0 m}$ at the crop site was favorable for higher $\Delta T_{\mathrm{s}}$, evaporation based on sufficient water supply reduced the Bowen ratio and cooled $T_{\mathrm{S}}$ efficiently in the summer.
The averages of observed $\Delta T_{\mathrm{S}}$ in the growing season were $-1.79^{\circ}$ at the crop site and $2.01^{\circ}$ at the urban site. At the crop site, the calculated $\Delta T_{\mathrm{S}}$ was $-1.76^{\circ}$ and the albedo and aerodynamic resistance contributions were 0.09 and $0.47^{\circ}$, but the Bowen ratio cooling effect decreased $\Delta T_{\mathrm{S}}$ by $1.40^{\circ}$. At the urban site, the calculated $\Delta T_{\mathrm{S}}$ was $1.25^{\circ}$, and the difference between the observed and calculated values, which was larger in the summer, was partly due to a lack of knowledge regarding heat storage and anthropogenic heating. Even if radiation and surface roughness cooling existed, the limited evaporation reduced the partitioning of $R_{\mathrm{n}}$ to latent turbulent heat flux and warmed the urban area by $2.29^{\circ}$.

Atmospheric feedback is also important. It can not only change the cloud distribution due to water and heat differences or aerosol effects and impact solar radiation (Yang et al., 2012; Betts et al., 2007; Biggs et al., 2008), but it can also affect circulations or the variation of vegetation physical properties such as albedo and evaporation (Niu et al., 2011; Yang et al., 2014) and subsequently affect $T_{\mathrm{s}}$. The atmospheric background effects of $T_{\mathrm{a}}$ were relatively stable and could not be neglected during the whole growing season. It had an average contribution of $-0.93^{\circ}$ to the cropland cooling effect and $0.54^{\circ}$ to the urban heat island effect and enlarged the difference in surface temperature induced by land use.

\section{Conclusions and discussions}

Our study presented firsthand observational evidence to verify the model results. Located in the East Asian monsoon region, the lower reaches of the Yangtze River have experienced the most intensive land use changes around the world, which has significant impacts on the local and regional cli- 
mate. However, these impacts may not be easy to quantify due to the lack of observations in this region and uncertainties in modeling results. We used in situ data to quantify the contributions of the two main land use types here (the irrigated cropland and the rapid urbanization) to the microclimate change. It shows that the crop cooling and UHI were both obvious. The differences in $T_{\mathrm{s}}$ were larger in the months with low precipitation, and the monthly maximum values at both sites are even larger than $2^{\circ}$.

For the study of LULCC effects on regional climate, more attention should be paid to non-radiative forces and the feedback from the background circulation. Although the surface albedo change caused by LULCC has been considered to be the strongest climate forcing and its effect has been widely and quantitatively estimated, other non-radiative modifications induced by LULCC, including roughness and evaporation, are also important. Our results show that the alteration of radiation, aerodynamic resistance, evaporation, and air temperature all contributed to $\Delta T_{\mathrm{S}}$ (Fig. 3). The contributions of aerodynamic roughness and the Bowen ratio, which are related to energy redistribution, are largely more than that of the net solar radiation. Despite the negative contributions of net solar radiation and aerodynamic resistance, the positive contribution of the Bowen ratio controlled both the cropland cooling effect and the urban heat island effect, which are enlarged by the influence of background atmospheric circulation.

These results demonstrate that the evaporative cooling effect is the most important factor that modifies the surface temperature change in the lower reaches of the Yangtze River valley, and the temperature change induced by this effect is even comparative to the total value of $\Delta T_{\mathrm{S}}$. There have been some studies based on the field data of North America and western Europe. They indicate that the effects of evaporation and convection usually dominate the land-atmosphere feedback of deforestation and urbanization in the mid to lower latitudes (Chen and Dirmeyer, 2016; Zhao et al., 2014). But at higher latitudes, the radiative forcing contributes more to the surface temperature change associated with the deforestation of boreal regions in North America (Lee et al., 2011) and Norway (Bright et al., 2014). Although the evaporative cooling and surface roughness are both important in landatmosphere interaction - even more than albedo changes in some regions at lower latitudes - their effects usually cannot be revealed accurately by models (IPCC, 2013) and the studies of these surface factor effects are still insufficient, especially in some regions with scarce in situ observations such as in the lower reaches of the Yangtze River. To better understand the local and regional climate change and the possible large-scale feedback (for example the feedback between land use change and the East Asian monsoon system), more observational data and accurate modeling studies of the physical mechanisms between the land surface and the atmosphere are needed for further theoretical analysis.
Data availability. For data used in our study, please contact the corresponding author, Weidong Guo (guowd@ nju.edu.cn).

Competing interests. The authors declare that they have no conflict of interest.

Acknowledgements. This research is jointly sponsored by the Natural Science Foundation of China (Grant No. 41475063, 91544231) and the National Science and Technology Support Program (2014BAC22B04). This work is also supported by the Jiangsu Collaborative Innovation Center for Climate Change.

Edited by: J. Huang

Reviewed by: two anonymous referees

\section{References}

Alkama, R. and Cescatti, A.: Biophysical climate impacts of recent changes in global forest cover, Science, 351, 600-604, 2016.

Baldocchi, D.: Biogeochemistry: Managing land and climate, Nature Climate Change, 4, 330-331, doi:10.1038/nclimate2221, 2014.

Baldocchi, D. and Ma, S.: How will land use affect air temperature in the surface boundary layer? Lessons learned from a comparative study on the energy balance of an oak savanna and annual grassland in California, USA, Tellus B, 65, 19994, doi:10.3402/tellusb.v65i0.19994, 2013.

Basara, J. B., Hall, P. K., Schroeder, A. J., Illston, B. G., and Nemunaitis, K. L.: Diurnal cycle of the Oklahoma City urban heat island, J. Geophys. Res., 113, D20109, doi:10.1029/2008jd010311, 2008.

Betts, A. K., Desjardins, R. L., and Worth, D.: Impact of agriculture, forest and cloud feedback on the surface energy budget in BOREAS, Agr. Forest Meteorol., 142, 156-169, 2007.

Bi, X., Gao, Z., Deng, X., Wu, D., Liang, J., Zhang, H., Sparrow, M., Du, J., Li, F., and Tan, H.: Seasonal and diurnal variations in moisture, heat, and $\mathrm{CO}_{2}$ fluxes over grassland in the tropical monsoon region of southern China, J. Geophys. Res.-Atmos., 112, 185-194, 2007.

Biggs, T. W., Scott, C. A., Anju, G., Jean-Philippe, V., Thomas, C., and Eungul, L.: Impacts of irrigation and anthropogenic aerosols on the water balance, heat fluxes, and surface temperature in a river basin, Water Resour. Res., 44, 181-198, 2008.

Bright, R. M., Anton-Fernandez, C., Astrup, R., Cherubini, F., Kvalevag, M., and Stromman, A. H.: Climate change implications of shifting forest management strategy in a boreal forest ecosystem of Norway, Glob. Change Biol., 20, 607-621, doi:10.1111/gcb.12451, 2014.

Bright, R. M., Zhao, K., Jackson, R. B., and Cherubini, F.: Quantifying surface albedo and other direct biogeophysical climate forcings of forestry activities, Glob. Change Biol., 21, 3246-3266, doi:10.1111/gcb.12951, 2015.

Campra, P., Garcia, M., Canton, Y., and Palacios-Orueta, A.: Surface temperature cooling trends and negative radiative forcing due to land use change toward greenhouse farming in southeastern Spain, J. Geophys. Res.-Atmos., 113, 1044-1044, 2008. 
Chen, J., Wang, J., and Mitsuta, Y.: An Independent Method to Determine the Surface Roughness Length, Chinese Journal of Atmospheric Sciences, 17, 21-26, 1993.

Chen, L. and Dirmeyer, P. A.: Adapting observationally based metrics of biogeophysical feedbacks from land cover/land use change to climate modeling, Environ. Res. Lett., 11, 034002, doi:10.1088/1748-9326/11/3/034002, 2016.

Davin, E. L. and Noblet-Ducoudré, N. D.: Climatic Impact of Global-Scale Deforestation: Radiative versus Nonradiative Processes, J. Climate, 23, 97-112, 2010.

Foken, T. and Wichura, B.: Tools for quality assessment of surfacebased flux measurements, Agr. Forest Meteorol., 78, 83-105, 1996.

Foken, T., Göockede, M., Mauder, M., Mahrt, L., Amiro, B., and Munger, W.: Post-Field Data Quality Control, Handbook of micrometeorology: a guide for surface flux measurement and analysis, 181-208, 2004.

Gao, Z.: Measurements of turbulent transfer in the near-surface layer over a rice paddy in China, J. Geophys. Res., 108, 4387, doi:10.1029/2002jd002779, 2003.

Guo, W., Wang, X., Sun, J., Ding, A., and Zou, J.: Comparison of land-atmosphere interaction at different surface types in the mid- to lower reaches of the Yangtze River valley, Atmos. Chem. Phys., 16, 9875-9890, doi:10.5194/acp-16-9875-2016, 2016.

Hari, P., Petäjä, T., Bäck, J., Kerminen, V.-M., Lappalainen, H. K., Vihma, T., Laurila, T., Viisanen, Y., Vesala, T., and Kulmala, M.: Conceptual design of a measurement network of the global change, Atmos. Chem. Phys., 16, 1017-1028, doi:10.5194/acp16-1017-2016, 2016.

Hsu, H. H. and Liu, X.: Relationship between the Tibetan Plateau heating and East Asian summer monsoon rainfall, Geophys. Res. Lett., 30, 1182-1200, 2003.

Huang, J., Zhang, W., Zuo, J., Bi, J., Shi, J., Wang, X., Chang, Z., Huang, Z., Yang, S., Zhang, B., Wang, G., Feng, G., Yuan, J., Zhang, L., Zuo, H., Wang, S., Fu, C., and Jifan, C.: An overview of the Semi-arid Climate and Environment Research Observatory over the Loess Plateau, Adv. Atmos. Sci., 25, 906-921, doi:10.1007/s00376-008-0906-7, 2008.

Huang, J., Yu, H., Guan, X., Wang, G., and Guo, R.: Accelerated dryland expansion under climate change, Nature Climate Change, 6, 166-171, doi:10.1038/nclimate2837, 2015.

IPCC: Climate Change 2013: The Physical Science Basis. Contribution of Working Group I to the Fifth Assessment Report of the Intergovernmental Panel on Climate Change, 1535 pp., Cambridge University Press, UK and New York, NY, USA, 2013.

Juang, J.-Y., Katul, G., Siqueira, M., Stoy, P., and Novick, K.: Separating the effects of albedo from eco-physiological changes on surface temperature along a successional chronosequence in the southeastern United States, Geophys. Res. Lett., 34, L21408, doi:10.1029/2007g1031296, 2007.

Kalnay, E. and Cai, M.: Impact of urbanization and land use on climate change, Nature, 1, 528-531, 2003.

Kanda, M.: Roughness Lengths for Momentum and Heat Derived from Outdoor Urban Scale Models, J. Appl. Meteorol. Clim., 46, 1067-1079, 2007.

Kueppers, L. M., Snyder, M. A., and Sloan, L. C.: Irrigation cooling effect: Regional climate forcing by land-use change, Geophys. Res. Lett., 34, 407-423, 2007.
Lee, X., Goulden, M. L., Hollinger, D. Y., Barr, A., Black, T. A., Bohrer, G., Bracho, R., Drake, B., Goldstein, A., Gu, L., Katul, G., Kolb, T., Law, B. E., Margolis, H., Meyers, T., Monson, R., Munger, W., Oren, R., Paw, U. K., Richardson, A. D., Schmid, H. P., Staebler, R., Wofsy, S., and Zhao, L.: Observed increase in local cooling effect of deforestation at higher latitudes, Nature, 479, 384-387, doi:10.1038/nature10588, 2011.

Li, H. Y., Fu, C. B., Guo, W. D., and Ma, F.: Study of energy partitioning and its feedback on the microclimate over different surfaces in an arid zone, Acta Phys. Sin., 64, 59201, doi:10.7498/aps.64.059201, 2015.

Lin, S., Feng, J., Wang, J., and Hu, Y.: Modeling the contribution of long-term urbanization to temperature increase in three extensive urban agglomerations in China, J. Geophys. Res.-Atmos., 121, 1683-1697, 2016.

Lobell, D. B., Bala, G., and Duffy, P. B.: Biogeophysical impacts of cropland management changes on climate, Geophys. Res. Lett., 33, 272-288, 2006.

Luyssaert, S., Jammet, M., Stoy, P. C., Estel, S., Pongratz, J., Ceschia, E., Churkina, G., Don, A., Erb, K., Ferlicoq, M., Gielen, B., Grünwald, T., Houghton, R. A., Klumpp, K., Knohl, A., Kolb, T., Kuemmerle, T., Laurila, T., Lohila, A., Loustau, D., McGrath, M. J., Meyfroidt, P., Moors, E. J., Naudts, K., Novick, K., Otto, J., Pilegaard, K., Pio, C. A., Rambal, S., Rebmann, C., Ryder, J., Suyker, A. E., Varlagin, A., Wattenbach, M., and Dolman, A. J.: Land management and land-cover change have impacts of similar magnitude on surface temperature, Nature Climate Change, 4, 389-393, doi:10.1038/nclimate2196, 2014.

McCarthy, M. P., Best, M. J., and Betts, R. A.: Climate Change in Cities Due to Global Warming and Urban Effects, Geophys. Res. Lett., 37, 232-256, 2010.

Moore, C. J.: Frequency response corrections for eddy correlation systems, Bound.-Lay. Meteorol., 37, 17-35, 1986.

Niu, G.-Y., Yang, Z.-L., Mitchell, K. E., Chen, F., Ek, M. B., Barlage, M., Kumar, A., Manning, K., Niyogi, D., Rosero, E., Tewari, M., and Xia, Y.: The community Noah land surface model with multiparameterization options (Noah-MP): 1. Model description and evaluation with local-scale measurements, J. Geophys. Res., 116, D12109, doi:10.1029/2010jd015139, 2011.

Pitman, A. J., Noblet-Ducoudré, N. D., Cruz, F. T., Davin, E. L., Bonan, G. B., Brovkin, V., Claussen, M., Delire, C., Ganzeveld, L., and Gayler, V.: Uncertainties in climate responses to past land cover change: First results from the LUCID intercomparison study, Geophys. Res. Lett., 36, 171-183, 2009.

Verhoef, A. and De Bruin, H. A. R.: Some Practical Notes on the Parameter kB-1 for Sparse Vegetation, J. Appl. Meteorol., 36, 560-572, 1997.

Wang, G., Huang, J., Guo, W., Zuo, J., Wang, J., Bi, J., Huang, Z., and Shi, J.: Observation analysis of land-atmosphere interactions over the Loess Plateau of northwest China, J. Geophys. Res., 115, D00K17, doi:10.1029/2009jd013372, 2010.

Webb, E. K., Pearman, G. I., and Leuning, R.: Correction of flux measurements for density effects due to heat and water vapour transfer, Q. J. Roy. Meteor. Soc., 106, 85-100, 1980.

Wilczak, J. M., Oncley, S. P., and Stage, S. A.: Sonic Anemometer Tilt Correction Algorithms, Bound.-Lay. Meteorol., 99, 127 150, 2001.

Xue, Y., Juang, H. M. H., Li, W. P., Prince, S., Defries, R., Jiao, Y., and Vasic, R.: Role of land surface processes in monsoon de- 
velopment: East Asia and West Africa, J. Geophys. Res.-Atmos., 109, 215-229, 2004.

Yang, K., Ding, B., Qin, J., Tang, W., Lu, N., and Lin, C.: Can aerosol loading explain the solar dimming over the Tibetan Plateau?, Geophys. Res. Lett., 39, L20710, doi:10.1029/2012GL053733, 2012.

Yang, K., Wu, H., Qin, J., Lin, C., Tang, W., and Chen, Y.: Recent climate changes over the Tibetan Plateau and their impacts on energy and water cycle: A review, Global Planet. Change, 112, 79-91, doi:10.1016/j.gloplacha.2013.12.001, 2014.

Yuan, W., Cai, W., Chen, Y., Liu, S., Dong, W., Zhang, H., Yu, G., Chen, Z., He, H., and Guo, W.: Severe summer heatwave and drought strongly reduced carbon uptake in Southern China, Scientific Reports, 6, 18813, doi:10.1038/srep18813, 2016.

Zeng, X. and Dickinson, R. E.: Effect of Surface Sublayer on Surface Skin Temperature and Fluxes, J. Climate, 11, 537-550, 1998.
Zhang, X., Xiong, Z., Zhang, X., Shi, Y., Liu, J., Shao, Q., and Yan, X.: Using multi-model ensembles to improve the simulated effects of land use/cover change on temperature: a case study over northeast China, Clim. Dynam., 46, 765-778, doi:10.1007/s00382-015-2611-4, 2015.

Zhang, Y., Liu, H., Foken, T., Williams, Q. L., Mauder, M., and Thomas, C.: Coherent structures and flux contribution over an inhomogeneously irrigated cotton field, Theor. Appl. Climatol., 103, 119-131, 2011.

Zhao, L., Lee, X., Smith, R. B., and Oleson, K.: Strong contributions of local background climate to urban heat islands, Nature, 511, 216-219, doi:10.1038/nature13462, 2014. 